\title{
A exclusão do significado
}

\author{
Silvana Matias Freire*
}

\begin{abstract}
RESUMO
O que provoca a curiosidade, o fascínio e, muitas vezes, o mal-estar que envolvem manifestações vocais desprovidas de significado? Neste trabalho, trato de uma dessas manifestações: a glossolalia. Pretendo abordar, em linhas gerais, os primeiros registros sobre a glossolalia e fazer uma reflexão sobre esse fenômeno de linguagem, tendo como referência alguns princípios da lingüística.

Palavras-chave: glossolalia, lingǘstica, significado, voz.
\end{abstract}

The exclusion of the meaning

\section{Abstract}

What causes curiosity, fascination and, sometimes, uneasiness involving nonsense vocal manifestations? In this article I deal with one of these manifestations: the glossolalia. I intend to approach the first writing registers about glossolalia and to discuss this language phenomenon based on some principles of linguistics.

KEY wORDS: glossolalia, linguistics, meaning, voice.

\section{INTRODUÇão}

O termo glossolalia, na definição encontrada no dicionário Houaiss (2001, p. 1459), significa "uma suposta capacidade de falar línguas desconhecidas durante transe religioso [...], um distúrbio de linguagem observado em doentes mentais que acreditam inventar uma linguagem nova". Mas esse termo pode também ser estendido a outras manifestações vocais como, por exemplo, os primeiros sons produzidos pelo bebê ou os sons produzidos nas brincadeiras que consistem em imitar a prosódia de uma língua estrangeira.

A glossolalia parece ser uma língua estrangeira desconhecida. Mas ela possui alguns aspectos que fazem dela apenas o simulacro de uma língua natural. Dentre eles destaco dois: 1.o aspecto estrutural - mais complexo nas

* Professora assistente de Língua Francesa do Cepae/UFG. E-mail: silvfreire@ig.com.br 
98 Revista Solta a Voz, v. 16, n. 1

línguas naturais; 2. a disjunção entre som e sentido-com a primazia do som, no caso da glossolalia em que "fala-se para não dizer nada".

\section{Primeiros Registros}

Os primeiros registros que se têm a respeito do falar em línguas estão em dois livros do Novo Testamento. Um deles é Atos dos Apóstolos, que narra a vinda do Espírito Santo. Após ter-se manifestado vivo aos apóstolos, durante quarenta dias, Jesus envia o Espírito Santo para dar suas instruções aos apóstolos e sua chegada é narrada da seguinte forma:

Chegando o dia de Pentecostes, estavam todos reunidos no mesmo lugar. De repente veio do céu um ruído, como se soprasse um vento impetuoso, e encheu toda a casa onde estavam sentados. Apareceram-lhes então uma espécie de línguas de fogo, que se repartiram e repousaram sobre cada um deles. Ficaram todos cheios do Espírito Santo e começaram a falar em outras línguas, conforme o Espírito Santo lhes concedia que falassem. (Bíblia Sagrada, 1957, p. 1414)

O outro livro é I Coríntios, em que Paulo, apóstolo de Cristo, é chamado a pregar aos coríntios. Em uma de suas pregações, São Paulo fala dos dons espirituais, que são manifestações particulares e variadas da ação do Espírito Santo entre os fiéis, das quais as principais são o dom de caridade, de profecia, de milagres e a "glossolalia" , ou seja, a faculdade de rezar em voz alta num estado de grande exaltação, proferindo sons incompreensíveis. $\mathrm{Na}$ pregação antes mencionada aparece uma referência à glossolalia: "Ainda que eu falasse as línguas dos homens e dos anjos, se não tiver caridade, sou como o bronze que soa, ou como o címbalo que retine" (Bíblia Sagrada, 1957, cap. 13, vers.1).

A partir dos anos 1960, houve uma retomada da prática glossolálica com a Renovação Carismática e, mais recentemente, também nas Igrejas Evangélicas que se expandiram de forma vertiginosa nos últimos anos. Courtine (1988, p. 8) propõe como explicação o ressurgimento da glossolalia religiosa o fato de que ela retorna num momento histórico em que há uma "desvalorização das instituições (eclesiásticas ou sociais) de fala; deterioração de usos e costumes, degradação das convenções da linguagem etc." 
Saindo do domínio religioso e passando para o lingüístico-acadêmico, encontramos uma extensa literatura a respeito da glossolalia realizada no final do século XIX por Théodore Flournoy, professor da Universidade de Genebra, que se dedicou ao estudo das "línguas" inventadas pela médium Hélène Smith. Para tanto, Flournoy solicitou a ajuda de alguns lingüistas, entre eles Saussure (Courtine, 1988, p. 17).

No entanto, após ter formulado uma série de observações (de cunho etimológico) sobre as produções glossolálicas de Hélène Smith, relacionando essas produções com o sânscrito e, posteriormente, com o francês (língua materna de Hélène Smith), Saussure (Courtine, 1988) recua em suas análises etimológicas. Especula-se que esse recuo deveuse ao temor de ser ridicularizado pelos pares, uma vez que, com o desenvolvimento da lingüística estrutural, tais análises passaram a ser censuradas por essa ciência.

Mais de meio século depois, Jakobson e Waugh (1980, p. 257) também trataram do tema, e definiram assim a glossolalia:

Como uma atividade de criação verbal ou quase verbal em que os sons da linguagem, totalmente desprovidos do papel discriminador do sentido, não deixam de estar destinados a um certo tipo de comunicação, dirigida a um público ou a uma divindade. (Tradução minha)

De acordo com esses lingüistas, um dos traços característicos dos enunciados glossolálicos está na junção de duas funções. Por um lado, esses enunciados ligam o mundo dos homens ao de Deus; por outro, são mensagens transmitidas pela divindade a uma assistência humana.

Jakobson e Waugh (1980, p. 264) observam a presença de uma semelhança entre os vocábulos dessa "estranha língua" e os vocábulos "misteriosos das canções infantis". Mais à frente, no item intitulado "L'art verbal des enfants", os autores sublinham que uma das características próprias dos poemas infantis é a importância relativamente grande dada à estrutura fonológica em que há uma incidência freqüente do non-sens. Ainda que não esteja se referindo à glossolalia, podemos ver nessa afirmação uma analogia entre a glossolalia e os versos infantis. 


\section{Revista Solta a Voz, v. 16, n. 1}

\section{A glossolalia como fenôMENo lingüístico}

Por produzir como efeito uma aparência de linguagem, tentamos abordar a glossolalia a partir de alguns princípios estabelecidos pela lingüística estrutural.

No enunciado glossolálico ocorre uma ruptura da ligação entre o som e o sentido, mesmo assim mantém-se um efeito de estrutura produzido por essa "língua", dando ao ouvinte a impressão de que se trata de uma língua estrangeira. A explicação para esse fato encontra-se numa questão mais geral que concerne à ligação da voz (elemento crucial da enunciação) com o signo (garantia de uma possível comunicação), sendo este último o fundamento da língua assim como de toda lingüística.

A posição singular que a glossolalia ocupa no campo das práticas enunciativas também chama a atenção. Ainda que não seja suficiente, pode-se dizer que o sujeito glossolálico é aquele que deseja falar uma língua "outra". Courtine (1988, p. 9) afirma:

a glossolalia coloca bem, se se considerá-la do ponto de vista de sua enunciação e não mais apenas como enunciado, a questão do sujeito enunciador de maneira incontornável. Ela desestabiliza e subverte toda referência enunciativa. Pois à simples interrogação: "Quem fala e para quem?" o glossolálico responderá: "É um Outro que não eu que fala; e esse Outro é também aquele para quem é endereçada minha fala, já que é a sua”. (Tradução minha)

Com essa citação uma questão se coloca à prática glossolálica: a questão da divisão do sujeito enunciador quando efetua a fala, pois a própria glossolalia é, ela mesma, a enunciação de uma tal divisão. Tal divisão, pode-se pensar, é a expressão do apagamento do "eu": isso fala pela minha voz.

A glossolalia restitui à língua, pela simulação, sua materialidade vocal, ou seja, corporal. Uma vez despojada do sentido, a língua proporciona ao sujeito a sensação de que o corpo ressoa com os barulhos da voz, relembrando às teorias do signo o seu fundamento: que o sujeito é falante.

De Certeau (1983, p. 10) chama a atenção para o fato de que a glossolalia não é um fenômeno totalmente excepcional. Ela pode ser 
entrevista "numa conversação comum: barulhos do corpo, citações de sons delinqüentes, fragmentos de vozes estranhas" que surgem subitamente na ordem das frases.

O discurso científico ou político, por exemplo, é pouco permeável a irrupções e a interrupções vocais em uma seqüência de proposições. Há um apagamento de gagueiras ocasionais, de hesitações, de tiques sonoros, lapsos. A conversação comum, ao contrário, "restaura a porosidade do discurso a esses barulhos outros", [e] tais barulhos que surgem nessas conversações "representam uma tatuagem interlocutória e vocal no discurso" (De Certeau, 1983, p. 10).

\section{AbordagEM LINGÜÍSTICA SOBRE A VOZ}

A lingüística estrutural, por sustentar um discurso científico, procurou eliminar do seu campo a porosidade do discurso. Para tanto, preocupou-se, primeiramente, em estabelecer um corte definitivo entre voz e língua, entre som e sentido, com o objetivo de chegar a uma definição precisa de língua. No Curso de lingüistica geral (1995, p. 15-16), Saussure estabeleceu essa separação para, posteriormente, definir a língua.

As sílabas que se articulam são impressões acústicas percebidas pelo ouvido, mas os sons não existiriam sem os órgãos vocais [...]. Não se pode reduzir então a língua ao som, nem separar o som da articulação vocal [...]. Mas admitamos que o som seja uma coisa simples: é ele quem faz a linguagem? Não, não passa de instrumento do pensamento e não existe por si mesmo.

Na definição de língua, Saussure (1995, p. 23) utiliza a noção de signo lingüístico quando afirma que a língua "constitui-se num sistema de signos onde, de essencial, só existe a união do sentido e da imagem acústica". No que se refere à imagem acústica, Saussure já havia advertido, algumas páginas antes, que é "fundamental observar que a imagem verbal não se confunde com o próprio som".

A teoria do signo despojou da língua o som, a voz (mas o que é a língua sem a voz?). A glossolalia toma o sentido inverso: trata de fazer com que os sons existam apenas em si mesmos. Ou seja, em relação à lingüística a glossolalia é a articulação de seu resto. 


\section{Revista Solta a Voz, v. 16, n. 1}

Courtine $(1988$, p. 9) explica que a dificuldade em considerar a possibilidade de produções vocais desprovidas de uma significação lingüística codificada, apagando o conteúdo próprio da voz e retendo apenas a informação que a vOz carrega, vem das posições simbólicas da voz e do corpo em relação às do sentido e da razão constituídas no nosso universo cultural.

Seguindo um preconceito racionalista, a voz é considerada como substância confusa e disforme. Ela é associada à origem da raça ou a um momento infantil do desenvolvimento individual, o que realça seu caráter regressivo, primitivo. A voz representaria, desse ponto de vista, a gênese da linguagem, momento em que os primeiros balbucios humanos começavam a se articular.

\section{ConClusão}

Dois aspectos marcaram momentos cruciais para a constituição da lingǘstica como ciência. Considero que tais aspectos têm uma relação paradoxal com duas características principais do fenômeno glossolálico. A primeira se refere ao ideal de comunicação e a segunda ao mito da origem da linguagem, como foi mencionado no item anterior.

O século XVII foi chamado, na história da lingüística, o século das gramáticas gerais, em que vigorava o racionalismo e a linguagem era considerada como representação do pensamento. Isto significava dizer que a linguagem deveria ser clara, precisa, livre de ambigüidade e equívoco, capaz, enfim, de garantir uma comunicação sem falhas.

O segundo momento-chave para o estabelecimento da lingüística como ciência foi o século XIX, com as gramáticas comparadas, com a busca pela língua-mãe, aquela que deu origem a todas as outras línguas existentes. Chegou-se assim ao chamado indo-europeu, uma língua hipotética, que teria dado origem às línguas conhecidas, que é uma reconstrução teórica, um conceito. Esses momentos revelam dois desejos do homem sabotados pela glossolalia.

Primeiro, o desejo de atingir um dizer unívoco e absoluto - em que ele possa dizer tudo. Nas palavras de Certeau (1983, p. 10), o sujeito da glossolalia '[...] fala 'para nada dizer', precisamente para não ser enganado pelas palavras, para escapar às armadilhas do sentido, 
por ser uma pura fábula (fari, falar) e acrescentar à sua antecedência um dizer primeiro" (tradução minha).

Segundo, o desejo de descobrir o elo que separou o humano do animal, momento em que o homem falou pela primeira vez e nessa via a glossolalia corresponderia

a uma simulação dos primeiros momentos da linguagem, uma representação de sua origem; mas também um mito de sua gênese, uma das formas imaginárias que toma, na história da linguagem, o eterno retorno do momento em que, pela primeira vez, o homem se põe a falar pela primeira vez. (Courtine, 1988, p. 8)

\section{REFERÊNCIAS}

BÍBLIA SAGRADA. São Paulo: Editora Ave Maria, 1957.

COURTINE, J-J. Les silences de la voix. Langages, Paris: Larousse, $\mathrm{n}$. 91, p. 7-25, set. 1988.

DE CERTEAU, M. Utopies vocales: glossolalies. Le discours psychanalytique, Paris, n. 7, p. 10-18, 1983.

HOUAISS, A. Dicionário Houaiss da língua portuguesa. Rio de Janeiro: Objetiva, 2001.

JAKOBSON, R.; WAUGH, L. La charpente phonique du langage. Paris: Les Editions de Minuit, 1980.

SAUSSURE, F. Curso de lingüística geral. São Paulo: Cultrix, 1995.

Recebido em: 8 abr. 2005

Aceito em: 10 maio 2005 